\title{
Educação ambiental aplicada aos resíduos sólidos em uma comunidade rural no estado de Minas Gerais, Brasil
}

No meio rural, são produzidas grandes quantidades de resíduos que, apesar de possuírem grande potencial, são descartados de forma inadequada, gerando impactos negativos ao meio ambiente e à saúde pública. Nesse contexto, a educação ambiental surge como importante instrumento, no tocante à gestão dos resíduos sólidos, possibilitando o desenvolvimento de conhecimento, atividades e habilidades necessárias à preservação ambiental. 0 presente estudo fo desenvolvido na comunidade rural Antônio Olinto, localizada no norte do estado de Minas Gerais, Brasil. Considerando que grande parte dos resíduos produzidos na comunidade são descartados inadequadamente, faz-se necessário desenvolver ações que promovam a conscientização dos moradores da comunidade. Desta forma, o presente estudo objetivou desenvolver ações que promovam a conscientização da população local, quanto aos riscos da disposição irregular de resíduos sólidos gerados, bem como propor alternativas para a gestão destes resíduos sólidos. Para tanto, foram realizadas visitas área da comunidade rural e nas residências dos moradores, com o propósito de identificar os principais impactos oriundos das atividades antrópicas e os principais problemas enfrentados pela comunidade local, decorrentes desses impactos. Além disso, a fim de promover o reaproveitamento dos resíduos orgânicos, foi desenvolvida uma oficina de compostagem que contou com a participação de diversos moradores. A partir dessas atividades com considerável participação dos moradores, foi evidenciado que a comunidade rural sofre com os efeitos da destinação inadequada de resíduos sólidos. Desta forma, as visitas nas residências, bem como a oficina de compostagem, possibilitaram a conscientização dos moradores no intuito de aderirem a um modelo para a gestão dos resíduos sólidos gerados, que visa à redução, reutilização e reciclagem dos resíduos sólidos, bem como a técnica de compostagem para aproveitamento dos resíduos orgânicos, visando o máximo aproveitamento do potencial dos resíduos gerados na comunidade.

Palavras-chave: Resíduos sólidos; Educação ambiental; Compostagem; Reciclagem.

\section{Environmental education applied to solid waste in a rural community in the state of Minas Gerais, Brazil}

\begin{abstract}
In rural areas, large quantities of waste are produced which, despite having great potential, are improperly disposed of, causing negative impacts on the environment and public health. In this context, environmental education emerges as an important instrument regarding solid waste management, enabling the development of knowledge, activities and skills necessary for environmental preservation. The present study was developed in the rural community Antônio Olinto, located in the north of Minas Gerais state, Brazil. Considering that much of the waste produced in the community is improperly disposed of, it is necessary to develop actions that promote the awareness of community residents. Thus, the present study aimed to develop actions that promote awareness of the loca population, regarding the risks of irregular disposal of solid waste generated, as well as propose alternatives for the management of this solid waste. To this end, visits were made to the area of ??the rural community and residents' homes to identify the main impacts from anthropic activities and the main problems faced by the local community resulting from these impacts. In addition, to promote the reuse of organic waste, a composting workshop was developed with the participation of several residents. From these activities with considerable participation of residents, it was shown that the rural community suffers from the effects of improper disposal of solid waste. In this way, the visits to the residences, as well as the composting workshop, made the residents aware so as to adhere to a model for the management of solid waste generated, which aims at the reduction, reuse and recycling of solid waste, as well as the composting technique for the use of organic waste, aiming to maximize the potential of the waste generated in the community.
\end{abstract}

Keywords: Solid waste; Environmental education; Composting; Recycling.

Topic: Educação Ambiental e Ensinos Multidisciplinares

Reviewed anonymously in the process of blind peer

Lucas Victor Pereira de Freitas

Universidade Federal de Minas Gerais, Brasil

http://lattes.cnpq.br/8191209040123763

lucasvictorfreitas@yahoo.com.br

Lucas David Rodrigues dos Santos

Faculdade de Ciências Farmacêuticas de Ribeirão Preto, Brasil

http://lattes.cnpq.br/4172870226372939

lukas.davyd@hotmail.com

Silvia Sthefany Moreira Rosa

Instituto Federal do Norte de Minas, Brasil

http://lattes.cnpq.br/0971384143373115

silviamoreira@hotmail.com.br

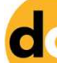

DOI: 10.6008/CBPC2318-2881.2019.002.0009
Received: 11/06/2019

Approved: 14/08/2019

\section{Bruna Emanuely Pereira Freitas \\ Instituto Educacional Santo Agostinho, Brasil \\ http://lattes.cnpq.br/5126377459036556}

bruna.emanuely13@gmail.com

João Paulo Fernandes Tiago

Universidade Federal de Minas Gerais, Brasil

http://lattes.cnpq.br/3407636284068575

i.paulo133@hotmail.com

\section{Referencing this:}

FREITAS, L. C. P. F.; SANTOS, L. D. R.; ROSA, S. S. M.; FREITAS, B. E. P.; TIAGO, J. P. F.. Educação ambiental aplicada aos resíduos sólidos em uma comunidade rural no estado de Minas Gerais, Brasil. Nature and Conservation, v.12, n.2, p.88-95, 2019. DOI:

http://doi.org/10.6008/CBPC2318-2881.2019.002.0009 


\section{INTRODUÇÃO}

A sensibilidade, no trato com as questões que envolvem o meio ambiente, tem se tornado uma necessidade a todos os seres humanos que habitam, consomem e, invariavelmente, poluem o planeta com resíduos provenientes de suas atividades. Segundo Santos Junior (2010), o que há pouco tempo era uma questão eminentemente urbana, também passou a ser um problema da área rural. Para Sobral (2009), o atual modelo de desenvolvimento, baseado no consumo acentuado, é predatório e coloca em segundo plano a preservação dos recursos naturais. Assim, a problemática ambiental vem ganhando cada vez mais destaque como um dos grandes problemas a ser enfrentado.

No decorrer das últimas décadas, todo um conjunto de práticas sociais voltadas para o meio ambiente, tem se instituído no âmbito das legislações e programas socioambientais, sendo uma dessas práticas a Educação Ambiental (CARVALHO, 2017). Conforme discutido por Dias et al. (2016), quando se discute sobre a educação, deve-se levar em consideração que é uma atividade complexa que necessita de estratégias bem traçadas para que possa obter resultados satisfatórios. De acordo com Silva (2012), a educação ambiental está presente na vida das pessoas desde o início de sua existência na terra, pois para sua sobrevivência era imprescindível ao homem saber relacionar-se com o meio ambiente.

Segundo Soares (2007), no Brasil a Educação ambiental esteve intimamente ligada a propostas pedagógicas promovidas junto às comunidades rurais, sendo que durante um longo período o campo foi considerado como um lugar de rusticidade, do inculto do atraso, entre outros atributos negativos. A educação ambiental também constitui um processo informativo e formativo dos indivíduos, fazendo com que possam desenvolver habilidades e modificar atitudes em relação ao meio ambiente (SOARES et al., 2007).

A finalidade da educação ambiental é despertar a preocupação individual e coletiva para a questão ambiental com uma linguagem de fácil entendimento que contribui para que o indivíduo e a coletividade construam valores sociais, atitudes e competências voltadas para a conservação do meio ambiente. Assim, torna-se necessário mudar o comportamento do homem com relação à natureza, com o objetivo de atender às necessidades atuais e futuras, no sentido de promover um modelo de desenvolvimento sustentável (SOARES et al., 2007). Portanto, um programa de educação ambiental eficiente deve promover, simultaneamente, o desenvolvimento de conhecimento, atividades e de habilidades necessárias à preservação e melhoria da qualidade ambiental (DIAS, 1992).

Um dos grandes problemas ambientais, principalmente em comunidades rurais, é a produção e disposição final de resíduos sólidos. Segundo a ABNT NBR 1004:2004, os resíduos sólidos são definidos como qualquer material no estado sólido e semissólido resultante de atividades agrícolas; comerciais; domésticas; hospitalares; industriais e de serviços de varrição, incluindo lodos oriundos de sistemas de tratamento de água; equipamentos; instalações de controle de poluição e determinados líquidos inviáveis para o lançamento na rede pública de esgotos ou corpos de água. 
A quantidade e diversidade de resíduos gerados relacionam-se a aspectos culturais; econômicos e sociais, os quais influenciam diretamente em sua constituição (MARSHALL et al., 2013). Dessa forma, é de extrema necessidade o gerenciamento dos resíduos, desde a coleta até a disposição final do rejeito (REZENDE et al., 2013).

No meio rural, normalmente, são produzidas grandes quantidades de resíduos que contêm, em sua composição, materiais que podem ser reciclados, tais como plásticos, vidro, papéis e metais. Sendo assim, o reaproveitamento dos resíduos antes de serem descartados, diminui o acúmulo destes no meio ambiente e com isso a poluição ambiental é minimizada, melhorando assim a qualidade de vida da população (FADINI et al., 2005). Diante do exposto, a redução na produção dos resíduos sólidos, bem como a sua correta destinação é um importante aliado na preservação do meio ambiente e da melhoria da qualidade de vida de populações rurais.

Segundo Darolt (2002), o lixo rural é composto tanto pelos restos vegetais da cultura e materiais associados à produção agrícola - como adubos químicos, defensivos e suas embalagens, dejetos animais, produtos veterinários - quanto por sobras semelhantes às produzidas nas cidades - como restos de alimentos, vidros, latas, papéis, papelões, plásticos, pilhas e baterias, lâmpadas etc.

Tendo em vista que no meio rural há uma menor quantidade de habitantes, estas regiões são diretamente afetadas pelos serviços públicos de saneamento, que são, muitas vezes, inexistentes em comunidades rurais. Conforme discutido por Pasquali (2012), a ausência da coleta de resíduos sólidos nas áreas rurais, tem como consequência o descarte inadequado dos resíduos pela população rural, seja queimando, enterrando ou simplesmente lançando em terrenos baldios.

A Lei Federal no 12.305 de 2010, instituiu a Política Nacional de Resíduos Sólidos (PNRS), que reúne o conjunto de diretrizes e ações a serem adotadas com vistas à gestão integrada e ao gerenciamento adequado dos resíduos sólidos. Esta lei aborda através da logística reversa a responsabilidade compartilhada, permitindo aos habitantes das zonas rurais devolverem parte dos resíduos sólidos, como resíduos e embalagens de agrotóxicos e óleos lubrificantes, pilhas, baterias e lâmpadas, aos distribuidores, a fim que possa ser feito o descarte adequado.

A PNRS estabelece, em seu art. 47, a proibição da queima e do lançamento de resíduos sólidos em cursos d'água ou a céu aberto (BRASIL, 2010). Apesar da queima e disposição dos resíduos sólidos a céu aberto serem práticas consideradas comuns no meio rural, elas são ilegais e provocam em impactos ao meio ambiente, sendo necessários ações para gerenciamento dos resíduos gerados. Nesse contexto, a educação ambiental surge como importante instrumento no tocante à gestão dos resíduos sólidos, possibilitando o desenvolvimento de conhecimento, atividades e habilidades necessárias à preservação e melhoria da qualidade ambiental, ao considerar que parte dos resíduos gerados pelas atividades humanas possui valor comercial, e sua gestão deve ser feita de forma correta.

A falta de um sistema de descarte consolidado e eficiente em inúmeras localidades rurais pode ocasionar sérios problemas ao ambiente, como a contaminação da água, do solo e até dos alimentos produzidos nas lavouras, dentre outros. O presente estudo foi desenvolvido na comunidade rural Antônio 
Olinto, localizada no norte do estado de Minas Gerais, Brasil. Considerando que grande parte dos resíduos produzidos na comunidade são descartados inadequadamente, faz-se necessário desenvolver ações que promovam a conscientização dos moradores da comunidade, bem como a proposição de alternativas de descarte dos diversos tipos de resíduos produzidos. Desta forma, o presente estudo objetivou desenvolver ações que promovam a conscientização da população da comunidade rural Antônio Olinto quanto aos riscos da disposição irregular de resíduos sólidos, bem como propor alternativas para a gestão dos resíduos sólidos gerados na comunidade.

\section{METODOLOGIA}

\section{Descrição da Área de Estudo}

A comunidade rural de Antônio Olinto está localizada no município de Montes Claros, situado no norte do estado de Minas Gerais, Brasil. Seu principal acesso se dá pela BR-135, e situa-se a aproximadamente dois quilômetros da área urbana, conforme figura 1. Atualmente, a comunidade conta com mais de 100 famílias, que estão cadastradas nos dados da associação de moradores local. Muitas destas famílias possuem como principal atividade de subsistência a agricultura familiar, comercializando na área urbana do município os produtos cultivados.

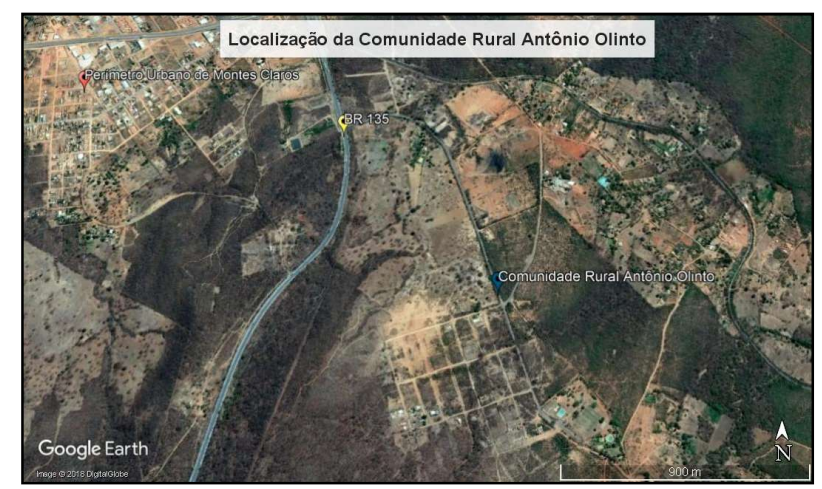

Figura 1: Mapa de localização da comunidade rural Antônio Olinto.

A destinação dos resíduos sólidos da comunidade rural é feita de forma inadequada, já que na região não é realizada a coleta regular. Além disso, diversos terrenos são feitos de depósito a céu aberto. Como o local está situado próximo à área urbana, ocorre o descarte de resíduo vindo de estabelecimentos urbanos e dos resíduos gerados pela própria população residente.

\section{Atividades Desenvolvidas na Comunidade Rural}

Foi realizada uma visita na visita na comunidade rural de Antônio Olinto, com o propósito de elaborar um diagnóstico com caráter exploratório descritivo. Para tanto, foi desenvolvida a análise de campo na comunidade para a verificação dos principais impactos oriundos das atividades antrópicas e os principais problemas enfrentados pela comunidade local, decorrentes desses impactos.

Após a elaboração do diagnóstico ambiental, onde foram identificados os principais problemas encontrados na comunidade, foram realizadas visitas nas residências dos moradores locais. A fim de propor 
um melhor aproveitamento dos resíduos orgânicos gerados na comunidade, foi proposto que o aproveitamento seja feito através da compostagem. Dessa forma, foi realizada uma oficina na residência de um morador local, contando com a participação dos moradores locais.

\section{RESULTADOS E DISCUSSÃO}

\section{Visita na Área de Estudo e Diagnóstico Ambiental}

Durante a visita na área da comunidade rural de Antônio Olinto, foram observados os seguintes problemas: Disposição inadequada e queima dos resíduos sólidos: em todo o percurso realizado na comunidade foi constatado grande acúmulo de resíduos sólidos em diversos pontos. Apesar de ter sido verificado que grande parte dos resíduos descartados nesses pontos eram gerados na própria comunidade, foi verificado que também haviam resíduos dispostos por pessoas que não residem da comunidade.

Mediante conversas com os moradores locais, foi informado pelos mesmos que é comum o descarte de resíduos sólidos oriundos da zona urbana, tendo em vista a facilidade no acesso da comunidade e a proximidade com o perímetro urbano. Como consequências da disposição inadequada dos resíduos sólidos tem-se a poluição do solo, ar, cursos de água e lençóis freáticos e o conjunto desses impactos gera a degradação do local, alterando a capacidade dos recursos ambientais de estabelecer-se naturalmente (AZEVEDO et al., 2015).

Além disso, foi verificado em muitos pontos, que é comum a queima dos resíduos sólidos por parte dos moradores. Cabe ressaltar que esta prática é proibida pela legislação em vigor (BRASIL, 2010), pois representa riscos à saúde da população, além de poluir o meio ambiente. Outro problema foi o fato de a comunidade contar com mais de 100 famílias, que estão cadastradas nos dados da associação de moradores local. Muitas destas famílias possuem como principal atividade de subsistência a agricultura familiar, comercializando na área urbana do município os produtos cultivados.

Além disso, ausência de consciência ambiental da população local. Foi verificado em vários pontos que os resíduos descartados são gerados na própria comunidade. Sendo assim, percebe-se uma falta de consciência ambiental por parte dos moradores da comunidade local a respeito dos impactos gerados pela disposição inadequada de resíduos sólidos.

Segundo Alcântara (2010), em áreas rurais, principalmente onde não há coleta domiciliar regular de lixo, os resíduos sólidos produzidos são queimados ou jogados de acordo com a conveniência e distância das residências, gerando depósitos sobre os quais provavelmente não há técnica adequada e cujas práticas de manejo realizadas pela população são desconhecidas. Portanto, é de fundamental importância a aplicação de práticas voltadas para despertar a conscientização dos moradores locais, para que assim possa reduzir impactos negativos sobre o meio ambiente e promover uma melhor qualidade de vida no meio inserido.

Outro problema é a ausência de técnicas para a redução de resíduos gerados. Foi verificado que grande parte dos resíduos descartados inadequadamente possuem potencial de reutilização e reciclagem. 
Também há uma grande quantidade de resíduos orgânicos, que podem ser utilizados para a adubação do solo e tratados em sistema de compostagem.

Desta forma, faz-se necessária uma capacitação dos moradores a respeito do reaproveitamento dos resíduos gerados, práticas de reciclagem, bem como o conhecimento de correto descarte dos resíduos sólidos gerados. Com relação ao reaproveitamento dos resíduos Penteado (2011) cita as seguintes possibilidades: reutilização de sacolas, sacos de papel, vidros, caixas de papelão ou plástico e papel de embrulho ou presente; aproveitamento do verso das folhas de papel usadas; restauração e conservação de objetos considerados velhos; doação de roupas, móveis, brinquedos e outros objetos que não tenham mais utilidade para o dono atual; e venda de peças ou equipamentos estragados a ferros-velhos, que possam reaproveitar partes.

A partir da educação ambiental dos moradores da comunidade de Antônio Olinto pode-se obter uma participação mais eficiente, de modo que os materiais recicláveis possam ser mais bem aproveitados e a eles dados uma destinação ambientalmente adequada, visando à redução do descarte sobre o meio ambiente e gerando renda para a população, uma vez que esse é um local onde residem muitas famílias carentes. Segundo Gonçalves et al. (2012), a educação ambiental é uma ferramenta que leva conhecimento e informação sobre saneamento, poluição por resíduos sólidos e preservação dos recursos naturais como prática fundamental à melhoria da qualidade de vida.

O incentivo às práticas de compostagem na comunidade poderá refletir na qualidade dos produtos gerados para ser comercializados na cidade, gerando benefícios a comunidade. Dentre as vantagens para a realização da compostagem, pode-se citar o baixo custo de instalação e operação, pois, além de utilizar a matéria orgânica presente nos resíduos sólidos como matéria-prima, é gerado um material rico em nutrientes que pode ser reaproveitado como composto ou fertilizante orgânico.

\section{Visita nas residências e elaboração de abaixo-assinado}

Foram realizadas visitas nas residências na comunidade rural, ocasião em que foi discutido com os moradores sobre a atual situação da disposição dos resíduos sólidos gerados. Percebe-se, de forma geral, que a queima dos resíduos gerados é principal forma de destinação dos resíduos pelos moradores locais. Desta forma, foi explicado aos moradores sobre os impactos dessa forma de destinação e foi proposto que o gerenciamento dos resíduos sólidos fosse feito através do reaproveitamento, reciclagem e coleta seletiva desses resíduos recicláveis.

De acordo com o INMETRO (2002), a reciclagem permite que os resíduos sólidos sejam transformados em novos produtos, utilizando-os como matéria-prima, e o reaproveitamento dos resíduos surge como alternativa eficiente uma vez que ao dar um novo uso aos objetos já utilizados, prolonga-se sua vida útil, ao mesmo tempo em que se reduz a poluição ambiental, além de proporcionar uma fonte de lucro. A coleta seletiva pode ser um instrumento de aumento na renda dos cidadãos, que podem realizar a venda desses produtos que são descartados. Este processo consiste na redução dos resíduos gerados por meio da segregação em categoriais, para posterior reaproveitamento, reutilização e reciclagem, visando à 
minimização de impactos ambientais e promovendo melhorias da qualidade de vida da população (SOUZA et al., 2015).

Para aproveitamento dos resíduos orgânicos, foi proposto aos moradores a técnica de compostagem, em que foi entregue um manual prático, explicando a técnica e como montar uma composteira. De acordo com o INMETRO (2002), através da compostagem os resíduos orgânicos podem ser transformados em adubos e rações de animais em usinas de compostagem ou mesmo nas residências.

Tendo em vista que na entrada principal da comunidade há uma grande quantidade de resíduos dispostos inadequadamente, foi elaborado um abaixo-assinado solicitando ao poder público municipal que seja feita a limpeza da área, e que seja feita a implantação de placas de conscientização e proibição do descarte de resíduos no local. Foram coletadas 76 assinaturas e o abaixo-assinado foi entregue à Associação de Moradores da Comunidade de Antônio Olinto, sendo posteriormente entregue à prefeitura do município de Montes Claros (MG).

\section{Oficina de Compostagem}

$\mathrm{Na}$ oficina de compostagem, realizada na residência de um morador local, foi repassado aos moradores um manual prático de como montar uma composteira doméstica. Nessa oficina, os moradores foram instruídos sobre como ocorre o processo da compostagem e quais os benefícios dessa prática, que possibilita a produção de adubo e fertilizante que podem ser utilizados nas pequenas plantações nas residências. A composteira foi devidamente montada e foram adicionados os compostos necessários para o processo.

Foi observado que alguns moradores não tinham o conhecimento das técnicas de compostagem, e se mostraram bastantes interessados nessa alternativa de aproveitamento dos resíduos. A compostagem pode ser considerada uma importante ferramenta para promover a redução do uso de fertilizantes na agricultura, sendo economicamente viável, se bem conduzida, e podendo ser responsável pela diminuição do potencial poluidor dos resíduos gerados (BARRENA et al., 2009; ARAÚJO et al., 2011). Sendo assim, foi entregue a cada um dos participantes, um manual autoexplicativo sobre a técnica de compostagem, constando a montagem, como proceder na adição dos resíduos orgânicos, e como deve ser a utilização dos compostos sólidos e líquidos gerados.

\section{CONCLUSÕES}

O presente projeto de educação ambiental na Comunidade Rural de Antônio Olinto possibilitou que fosse feito o diagnóstico ambiental na comunidade rural. Foi evidenciado que grande parte dos resíduos na entrada da comunidade são dispostos por pessoas que não residem na comunidade. Sendo assim, foi feito um abaixo-assinado solicitando ao poder público que seja feita a limpeza da área e a implantação de placas proibitivas no local.

Foram realizadas visitas nas residências, ocasião em que foi proposta para os moradores um modelo para a gestão dos resíduos sólidos gerados na comunidade, que visa a redução, reutilização, reciclagem e 
tratamento dos resíduos sólidos, bem como a técnica de compostagem para aproveitamento dos resíduos orgânicos gerados. Desta forma, a gestão de resíduos sólidos na comunidade rural foi baseada nos princípios do reaproveitamento, reciclagem e na compostagem caseira, visando, assim, o máximo aproveitamento do potencial dos resíduos gerados na comunidade.

\section{REFERÊNCIAS}

ABNT. Associação Brasileira de Normas Técnicas. NBR 10.004: Resíduos Sólidos: Classificação. Rio de Janeiro: ABNT, 2010.

ALCANTARA, P. F.. Concepções de resíduos sólidos em áreas rurais de Nova Friburgo (RJ, Brasil): do consumo ao manejo. Dissertação (Mestrado em Ciências) - Fundação Oswaldo Cruz, Rio de Janeiro, 2010.

ARAÚJO, F. B.; SANES, F. S. M.; STRASSBURGUER, A. S.; MEDEIROS, C. A. B.. Avaliação de adubos orgânicos elaborados a partir de resíduos de pescado, na cultura do feijão (Phaseulosvulgaris). In: CONGRESSO BRASILEIRO DE AGROECOLOGIA, 7. Anais. Fortaleza: Cadernos de Agroecologia, 2011.

AZEVEDO, P. B.; LEITE, J. J. C. A.; OLIVEIRA, W. S. N.; SILVA, F. M.; FERREIRA, P. M. L.. Diagnóstico da degradação ambiental na área do lixão de Pombal-PB. Verde, v.10, n.1, p.20-34, 2015. DOI: https://doi.org/10.18378/rvads.v10i1.3294

BARRENA, R.; ARTOLA, A.; VÁZQUEZ, F.; SÁNCHEZ, A.. The use of composting for the treatment of animal by-products: experiments at lab scale. Journal of Hazardous Materials, v.161, p.380-386, 2009. DOI:

https://doi.org/10.1016/j.jhazmat.2008.03.109

BRASIL. Lei n.12.305 de 02 de agosto de 2010. Política Nacional de Resíduos Sólidos. Brasília, DF. DOU, 2010.

CARVALHO, I. C. M.. Educação Ambiental a formação do sujeito ecológico. São Paulo: Cortez, 2017.

DAROLT, M. R.. Lixo rural: do problema à solução. Revista Eletrônica de Jornalismo Científico, n.95, 2008.

DIAS, G. F.. Educação Ambiental: princípios e práticas. Brasília: 1992.

DIAS, L. S.; LEAL, A. C.; CARPI JUNIOR, S.. Educação Ambiental, conceitos, metodologias e práticas. Tupã: 2016.

FADINI, P. S.; FADINI, A. A. B.. Lixo: desafios e compromissos. São Paulo: 2005

GONÇALVES, M. S.; KUMMER, L.; PATEL, A. G.; SOUZA, D. C. R.; FROSI, D.; FURIGO, M.; SAVEGNAGO, L.; TONIAZZO, F.. Educação ambiental em saneamento rural. Engenharia Ambiental, Espírito Santo do Pinhal, v.10, n.2, p.255-260, 2013.
INMETRO. Instituto Nacional de Metrologia, Qualidade e Tecnologia. Publicidade e consumo. Rio de Janeiro: Idec, 2002.

MARSHALL, E. R.; FARAHBAKHSH, K.. Systems Approaches to Integrated Solid Waste Management in Developing Countries. Waste Management, v.33, p.988-1003, 2013. DOI: https://doi.org/10.1016/j.wasman.2012.12.023

PASQUALI, L.. Composição gravimétrica de resíduos sólidos recicláveis domiciliares no meio rural de Chopinzinho/PR. Dissertação (Mestrado em Desenvolvimento Regional) Universidade Tecnológica Federal do Paraná, Pato Branco, 2012.

PENTEADO, M. J.. Guia pedagógico do lixo. 6 ed. São Paulo: SMA, 2011

REZENDE, J. H.; CARBONI, M.; MURGEL, M. A. T.; CAPPS, A. L. A. P.; TEIXEIRA, H. L.; SIMÕES, G. T. C.; RUSSI, R. R.; LOURENÇO, B. L. R.; OLIVEIRA, C. A.. Composição gravimétrica e peso específico dos resíduos sólidos urbanos em Jaú (SP). Engenharia Sanitária Ambiental, v.18, n.1, p.18, 2013. DOI: https://doi.org/10.1590/S141341522013000100001

SANTOS JÚNIOR, J. A.; BARROS JÚNIOR, G.; SANTOS, R. T.; LIMA, J. K. S.; BRITO, E. T. F. S.. Resíduos sólidos: o desafio da educação ambiental na comunidade rural de Uruçú Gurinhém/PB. Revista Educação Ambiental, n.982, 2010.

SILVA, M. N.. A educação ambiental na sociedade atual e sua abordagem no ambiente escolar. Florianópolis: UFSC, 2012.

SOARES, L. G. C.; SALGUEIRO, A. A.; GAZINEU, M. H. P.. Educação ambiental aplicada aos resíduos sólidos na cidade de Olinda, Pernambuco-um estudo de caso. Ciências \& Tecnologia, São Paulo, v.1, n.1, 2007.

SOARES, N. B.. Environmental education in the rural space: study of environmental practices of the state. Cacequi: 2007.

SOBRAL, C. R. S.. Educação ambiental e resíduos sólidos: possibilidades para a construção de um pensamento crítico. In: CONGRESSO DE MEIO AMBIENTE DA AUGM, 6. Anais. São Carlos: UFSC, 2009.

SOUZA, M.C.B.; MELLO, I.S.; Resíduos sólidos: coleta seletiva estímulo para o aumento da reciclagem e melhoria de renda dos catadores. Revista Eletrônica Gestão \& Saúde, v.6, n.3, p.59-81, 2015.

A CBPC - Companhia Brasileira de Produção Científica (CNPJ: 11.221.422/0001-03) detém os direitos materiais desta publicação. Os direitos referem-se à publicação do trabalho em qualquer parte do mundo, incluindo os direitos às renovaç̃̃es, expansões e disseminacõos da contribuição, bem como outros direitos subsidiários. Todos os trabalhos publicados eletronicamente poderão posteriormente ser publicados em coletâneas impressas sob coordenação da Sustenere Publishing, da Companhia Brasileira de Produção Científica e seus parceiros autorizados. Os (as) autores (as) preservam os direitos autorais, mas não têm permissão para a publicação da contribuição em outro meio, impresso ou digital, em português ou em tradução. 